\title{
Erratum to: Enzymatic oligomerization and polymerization of arylamines: state of the art and perspectives
}

\author{
Gordana Ćirić-Marjanović ${ }^{1}$ - Maja Milojević-Rakić ${ }^{1}$ - Aleksandra Janošević-Ležaić ${ }^{2}$ • \\ Sandra Luginbühl ${ }^{3} \cdot$ Peter Walde $^{3}$
}

(C) Institute of Chemistry, Slovak Academy of Sciences 2017

\section{Erratum to: Chem. Pap. (2017) 71:199-242 DOI 10.1007/s11696-016-0094-3}

The original article was published Online First without open access. After publication in volume 71, issue 2, page 199-242 the author decided to opt for Open Choice and to make the article an open access publication. Therefore, the copyright of the article has been changed to (C) The
Author(s) 2017 and the article is forthwith distributed under the terms of the Creative Commons Attribution 4.0 International License (http://creativecommons.org/licen ses/by/4.0/), which permits use, duplication, adaptation, distribution and reproduction in any medium or format, as long as you give appropriate credit to the original author(s) and the source, provide a link to the Creative Commons license, and indicate if changes were made.

The online version of the original article can be found under doi:10.1007/s11696-016-0094-3.

Gordana Ćirić-Marjanović

gordana@ffh.bg.ac.rs

1 Faculty of Physical Chemistry, University of Belgrade, Studentski Trg 12-16, 11158 Belgrade, Serbia

2 Department of Physical Chemistry and Instrumental Methods, Faculty of Pharmacy, University of Belgrade, Vojvode Stepe 450, 11221 Belgrade, Serbia

3 Department of Materials, ETH Zürich, Vladimir-Prelog-Weg 5, 8093 Zurich, Switzerland 